\title{
Externalismo ativo e convergência tecnológica NBIC: o advento da hipercognição
}

\author{
Kleber Bez Birolo Candiotto ${ }^{1}$ \\ Murilo Karasinski ${ }^{2}$
}

\begin{abstract}
Resumo: Este artigo tem por objetivo sustentar a hipercognição, resultado da interação da cognição humana com os artefatos interativos provenientes da Convergência Tecnológica NBIC (nano-bio-info-cogno), como perspectiva factível perante as teses pós-humanistas que esboçam uma transformação ontológica do ser humano a partir da fusão com máquinas. A factibilidade da hipercognição está alicerçada na concepção de cognição sustentada pelo externalismo ativo, em especial o de Andy Clark, para o qual o ambiente possui características relevantes o suficiente para desempenhar um papel protagonista no processo de cognição, uma vez que os humanos já seriam, por natureza, peritos na tarefa de incorporar material não biológico em suas rotinas físicas e cognitivas. A simbiose entre humanos (genuínos ciborgues tecnológicos) e máquinas seria algo que decorreria naturalmente, sobretudo na acepção de que os processos cognitivos seriam dependentes de ajuda externas. No contexto da Convergência Tecnológica NBIC, essa simbiose é o que possibilita a hipercognição.
\end{abstract}

Palavras-chave: Externalismo ativo. Convergência Tecnológica. Hipercognição.

\begin{abstract}
This article aims to support hypercognition, the result of the interaction of human cognition with interactive artifacts from Convergence Technology NBIC (nano-bio-info-cogno), as a feasible perspective in the face of post-humanist theses that outline an ontological transformation of the human being from the fusion with machines. The feasibility of hypercognition is based on the conception of cognition supported by active externalism, especially that of Andy Clark, for which the environment has relevant enough characteristics to play a leading role in the cognition process, since humans would already be, by nature, experts in the task of incorporating non-biological material into their physical and cognitive routines. The symbiosis between humans (genuine technological cyborgs) and machines would be something that would happen naturally, especially in the sense that cognitive processes would be dependent on external aids. In the context of the NBIC Technological Convergence, this symbiosis is what enables hypercognition.
\end{abstract}

Keywords: Active externalism. Technological Convergence. Hypercognition.

A tese da singularidade de Ray Kurzweil obteve grande notoriedade entre as abordagens transumanistas recentes. Em sua obra The Singularity is near, Kurzweil conjectura a singularidade tecnológica para o ano de 2045, quando “[...]a inteligência não biológica será um bilhão de vezes mais poderosa que toda a inteligência humana atual" (2005, p. 136). Nessa perspectiva, os seres humanos irão transcender as limitações biológicas de seus cérebros e corpos, passando a ter controle sobre a vida e a morte, o que

\footnotetext{
${ }^{1}$ Doutor em Filosofia pela Universidade Federal de São Carlos (UFSCar). Professor do Programa de PósGraduação em Filosofia da Pontifícia Universidade Católica do Paraná (PUCPR).

${ }^{2}$ Mestre e doutorando em filosofia pela PUCPR. Professor do Curso de Graduação em Filosofia da PUCPR.
} 
os permitiria viver por quanto tempo desejassem. Logo, a singularidade representaria o ponto culminante da fusão entre as inteligências humana e artificial, de tal forma que “[...]não haverá distinção, pós-singularidade, entre humano e máquina ou entre realidade física e realidade virtual" (Kurzweil, 2005, p. 09).

Com base no externalismo ativo, do ponto de vista cognitivo, a singularidade poderia ser considerada uma hipótese superestimada. Propõe-se, neste artigo, que a tese da hipercognição apresenta uma perspectiva factível, tendo em vista o mútuo desenvolvimento cognitivo humano com seu coagente cognitivo, a superinteligência, resultado das tecnologias NBIC (nano-bio-info-cogno). Compreende-se por hipercognição a capacidade cognitiva aumentada em grandes proporções por conta da interação da cognição humana com novos artefatos interativos, especialmente a inteligência artificial. Parte-se da perspectiva de que a cognição humana alcança grandes capacidades não por si mesma, mas pela sua aptidão natural de interação com o ambiente externo, constituindo um sistema cognitivo. Um ambiente externo que tenha presente resultados das tecnologias NBIC promove, assim, uma "explosão" cognitiva: tese da hipercognição aqui defendida.

De acordo com Jim Spohrer (2003, p. 102), cientista da computação e um dos líderes de projetos da International Business Machines (IBM), os avanços na nanotecnologia (obscurecendo os limites entre sistemas moleculares naturais e artificiais), nas ciências da informação (gerando máquinas inteligentes e autônomas), nas biociências e ciências da vida (estendendo a vida humana por meio da genômica) e nas ciências cognitivas e neuronais (criando redes neurais artificiais e decodificando o funcionamento do cérebro) teriam condições de mudar o ser humano da mesma maneira como a linguagem alterou o rumo da espécie há cem mil gerações. Uma dessas consequências, como se sustenta, é a própria hipercognição. Isso porque, segundo Roco e Bainbridge (2003, p. ix), os seres humanos, por via da Convergência Tecnológica, estariam em condições ímpares de compreender o mundo natural e a sociedade humana como sistemas hierárquicos e complexos, mas também conectados entre si, permitindose, em última instância, uma melhora da performance do Homo sapiens através da integração com NBIC, com destaque para seis campos de aplicação mais importantes: 1) expansão da cognição; 2) aprimoramento físico/biomedicina; 3) robótica/dispositivos 
inteligentes; 4) interface homem-máquina; 5) unificação da ciência e da educação e 6) modelagem computacional do planeta Terra.

De acordo com Nick Bostrom e Anders Sandberg (2010, p. 388-9), antes da invenção da escrita o cérebro do Homo sapiens não enfrentava nenhuma pressão evolutiva para ser literato. No mundo do século XXI, todavia, altos níveis de cognição seriam essenciais para atividades básicas, como entender o noticiário e preencher formulários, sem embargo das profissões que exigem compreensões mais profundas de estatística, cálculo ou geometria. Para os autores (2010, p. 389), uma vez que a linguagem escrita seria uma invenção relativamente recente, datando de 3.500 anos, e seu uso como meio de comunicação dominante ainda mais novo, não causaria estranheza que o cérebro humano fosse inadequado para as condições modernas.

A tese da hipercognição aqui defendida tem como premissa o argumento de que o ambiente, e especialmente as tecnologias NBIC da Convergência Tecnológica, conforme será apresentado mais adiante, contribui para o aumento e alteração da capacidade cognitiva dos seres humanos.

Para que se possa detalhar como esse processo ocorre, o ponto de partida se situa nas teorias cognitivas denominadas externalistas. Neste sentido, será feita inicialmente uma distinção entre o externalismo passivo, encontrado no pensamento de filósofos como Hilary Putnam (externalismo semântico) e Tyler Burge (externalismo social), e o externalismo ativo, de Andy Clark e David Chalmers, que culmina na proposta da mente estendida, a qual é o fundamento para a tese da hipercognição. Na sequência, após a análise de críticas a tais visões externalistas, sobretudo com os argumentos internalistas de Fred Adams e Ken Aizawa, haverá uma síntese demonstrando como essas objeções podem ser afastadas. Além disso, será defendido, a partir de Clark, que os seres humanos já são dotados de uma profunda plasticidade neural que fornece a habilidade para fusões e expansões da mente. Desse modo, a união do homem com os artefatos/instrumentos/tecnologia apenas segue o rumo natural da condição biológica original humana. Logo, o temor do transumanismo (o projeto de melhoramento humano) ou do pós-humanismo apocalíptico, no sentido de dissolução do humano frente aos avanços da tecnologia (Santaella, 2015, p. 21), não se justifica, o que será sustentado neste texto. 
O experimento mental proposto por Mark Rowlands (2003, p. 1) ilustra o que pode ser entendido por internalismo. Assim como no filme "Fantastic Voyage", de 1966, em que pesquisadores viajam miniaturizados em uma nave pelo corpo de outro cientista, é imaginada a hipótese de desenvolvimento de um dispositivo de tunelamento quântico por meio do qual uma viagem corporal fosse possível. Logo, no experimento mental, Rowlands (2003, p. 1) explora um indivíduo que opta por adentrar o corpo de outra pessoa através do crânio. "Primeiro você faz seu caminho pela pele: os limites entre a sua vítima/sujeito experimental e o mundo exterior. Isso é fácil” (Rowlands, 2003, p. 1). Na sequência, após romper uma segunda barreira mais compacta (do crânio), tal indivíduo tem acesso à matéria cinzenta e gelatinosa que é o cérebro. "Na verdade, no seu novo tamanho celular, pode não parecer cinza e pegajoso. Tempestades elétricas podem muito bem cercá-lo, seu navio é um galeão fantasmagórico lançado em mares nublados e químicos" (Rowlands, 2003, p. 1). Na suposição de Rowlands (2003, p. 1), o indivíduo ficaria dentro do cérebro por anos, ocasião em que teria a chance de mapear como as pequenas frações desse mundo se conectariam para formar as partes maiores; como os impulsos eletroquímicos viajariam e interagiriam entre si e, em resumo, como se organizaria a estrutura bruta e os componentes funcionais do órgão.

Ao regressar da viagem, o indivíduo começaria a refletir, segundo Rowlands (2003, p. 2), sobre todas as suas observações e, com base nas evidências acumuladas, concluiria - descrevendo o cérebro em sua complexidade global, com a identificação dos padrões elétricos, com a interpretação da atividade química e com a decodificação do modelo cerebral - que o conjunto daquelas características representaria, a rigor, a identificação da própria mente e de seus eventos, estados e processos. Tal ponto de vista, se mantido, corresponderia, de acordo com Rowlands (2003, p. 2), à posição internalista, que sustentaria que todos os estados mentais estariam localizados dentro da cabeça. Em contrapartida, de forma sucinta ${ }^{3}$, o externalismo seria a posição antitética, cuja perspectiva estaria em afirmar que "[...] nem todas as coisas mentais estão localizadas exclusivamente dentro da cabeça da pessoa ou da criatura que as possui" (Rowlands, 2003, p. 2). A tese da hipercognição se filia ao modelo externalista. Pretende-se demonstrar, como se verá, que são justamente as extensões da mente para além da

\footnotetext{
${ }^{3}$ Uma discussão pormenorizada sobre a diferença entre internalismo e externalismo, bem como dos tipos de externalismo, pode ser encontrada no artigo "Varieties of Externalism" (Carter et al., 2014).
} 
estrutura física do cérebro, na forma dos aparatos cognitivos da Convergência Tecnológica, que permitem o aumento da cognição.

Em termos didáticos, o externalismo se divide em externalismo passivo (com suas versões semântica e social ${ }^{4}$ ) e externalismo ativo. Embora a abordagem passiva do externalismo contenha elementos que contribuam para a compreensão da hipercognição, será tratado neste artigo o externalismo ativo, por conter argumentos diretamente relacionados ao desenvolvimento cognitivo integrado.

Acerca da tese da hipercognição, ainda que o externalismo semântico aponte que os significados não estão na cabeça e que o externalismo social traga à discussão o antiindividualismo, entende-se que o externalismo passivo é condição necessária, mas não suficiente para a hipercognição. Isso por dois motivos conectados: o primeiro porque, com base na premissa de Rowlands (2003, p. 154), o externalismo passivo se aplicaria somente a uma pequena porção daquilo que se passa no mental, seu escopo seria restrito e não abarcaria, por exemplo, enfrentamento de temas relativos aos processos e à arquitetura cognitiva. O segundo, como consequência do primeiro, na esteira do pensamento de Clark e Chalmers (1998), pela razão de que apenas no externalismo ativo estariam lançadas as bases conceituais para fundamentar que o ambiente possui características relevantes o suficiente para desempenhar um papel protagonista no

\footnotetext{
${ }^{4}$ O externalismo semântico é explicitado por Hilary Putnam (1975, p. 215), em "Language and Reality", com o argumento de que a linguagem seria a primeira capacidade cognitiva humana para a qual já se teria obtido um entendimento que não fosse apenas mera simplificação. Com o argumento da Terra Gêmea, Putnam (1975, p. 220) procurou combater aquilo que se convencionou chamar de "solipsismo metodológico", isto é, a ideia de que os estados psicológicos (ou estados mentais) poderiam ser obtidos independentemente da interação com fatores ambientais ou sociais. Haveria, a rigor, fatores externos responsáveis pela fixação de conteúdos mentais. Como apresenta Floyd (2005, p. 17), a proposta de Putnam seria uma resposta ao argumento de que quando a crenças mudam (como no caso da evolução das ciências) haveria também uma alteração nos significados e referentes dos termos. Putnam (2013) asseverou que o externalismo semântico congregaria ao menos duas propostas: a) que deveria ser abandonada a ideia de que os termos precisariam ter definições exatas e imutáveis e que seriam, nesse entendimento equivocado, tais definições que fixariam suas referências; b) que seria, em contrapartida, a combinação de teorias e experimentos a responsável por dizer o que cada termo significaria. O externalismo social, apresentado por Tyler Burge (1979; 1986) nos artigos "Individualism and the Mental" e "Individualism and Psychology", trabalha com o argumento de que a natureza da representação dos estados mentais dependeria da relação com um ambiente mais amplo. Com o experimental mental do indivíduo com artrites, Burge (1979, p. 79) sustenta que o conteúdo mental do paciente seria diferente a despeito da história física e mental continuar a mesma. Em outras palavras, os estados mentais podem variar em decorrência de modificações no ambiente, ainda que para a história do indivíduo tudo permaneça constante (Burge, 1986, p. 6). "As diferenças parecem originar-se de diferenças 'externas' ao paciente considerado como organismo físico isolado, mecanismo causal ou sede da consciência" (Burge, 1979, p. 79). Desse modo, "[...] a diferença em seu conteúdo mental é atribuível a diferenças em seu ambiente social” (Burge, 1979, p. 79).
} 
processo de cognição. Como argumentam Clark e Chalmers (1998), em alusão à icônica frase de Putnam, "cognitive process ain't (all) in the head!" ("os processos cognitivos não estão (somente) na cabeça"). Sem retirar a importância do externalismo passivo, que continuará presente nas bases conceituais da hipercognição, o foco e fundamento desta reflexão concentra-se no externalismo ativo.

Assim como o externalismo passivo comportava divisões metodológicas, o externalismo ativo é marcado por diferentes correntes desenvolvidas ao longo da pesquisa nas ciências cognitivas. Anteriormente ao artigo "The Extended Mind", de Andy Clark e David Chalmers (1998), que pode ser considerado um marco na investigação do externalismo ativo, muitas publicações já antecipavam os debates acerca da função do ambiente no processo cognitivo. Em 1985, por exemplo, Lucy Suchman, na obra Plans and Situated Actions, ${ }^{5}$ afirmava que o problema da inteligibilidade mútua definira o campo dos estudos sociais pelos últimos cem anos. Porém, segundo Suchman (1985, p. 3), enquanto esses estudos haviam se preocupado somente com a ação humana, o final do século XX seria marcado pelo surgimento de tecnologias que trariam a ideia de que o ser humano não apenas utilizaria máquinas, mas também interagiria com elas, motivo pelo qual seria necessário se investigar as bases de tal inteligibilidade mútua entre humanos e máquinas, ainda mais quando esses artefatos interativos, na expressão de Suchman (1985, p. 7), começassem a ter propósito e inteligência. “Agora, pela primeira vez, o termo interação - em um sentido anteriormente reservado para descrever uma atividade unicamente interpessoal - parece caracterizar adequadamente o que acontece entre pessoas e certas máquinas" (Suchman, 1985, p. 7) ${ }^{6}$.

\footnotetext{
${ }^{5}$ Em 2007, Suchman lançou uma segunda edição (revista e ampliada) da obra, afirmando que, depois de quase duas décadas da publicação do original, o estudo da temática continuava tão atraente e relevante quanto nunca, sobretudo com a pletora de avanços no campo da inteligência artificial e da interação ser humano-computador.

${ }^{6}$ Entre Suchman e Hutchins, outras significativas contribuições antecedentes à publicação de Clark e Chalmers (1998) poderiam ser mencionadas. Em 1986, James McClelland, David Rumelhart e Geoffrey Hinton (1986, p. 3), ao argumentarem sobre as distinções entre programas computacionais e seres humanos, ressaltaram que estes seriam muito melhores em perceber objetos em cenas naturais e em capturar suas relações; em compreender a linguagem e em armazenar informações apropriadas ao contexto; em fazer planos e agir de maneira correspondente às situações e assim por diante, nos mais diversos espectros de tarefas cognitivas. Para esses autores (1986, p. 46), o ambiente externo se tornaria uma extensão chave para a mente e ajudaria os indivíduos a empregar as habilidades motoras e perceptuais na resolução de problemas abstratos, mitigando os desafios em uma série de etapas menores e relativamente mais simples. Além disso, “[...] uma vez criada uma representação externa, ela pode ser reinterpretada sem levar em consideração sua interpretação inicial" (Rumelhart et al., 1986, p. 47), o que levaria, por sua vez, à descoberta de soluções “[...] para problemas sem 'ver' nosso caminho até o fim" (Rumelhart et al., 1986, p. 48). No final dos anos
} 
Em 1995, com a publicação de "Cognition in the Wild", Edwin Hutchins apresentou a proposta que talvez mais se aproximou dos conceitos defendidos por Clark e Chalmers. Isso porque, para Hutchins (1995, p. xiii), a atividade cognitiva deveria ser tomada a partir de um contexto, sendo que este não poderia ser um conjunto fixo de condições do entorno; pelo contrário, deveria consistir em "[...] um processo dinâmico mais amplo do qual a cognição de um indivíduo é apenas uma parte" (Hutchins, 1995, p. xiii). Com efeito, na perspectiva de Katherine Hayles (1999, p. 288), o estudo meticuloso de Hutchins acerca de preceitos de navegação o permitiu desenvolver a proposta, explicitada em "Cognition in the Wild", de que os sistemas de cognição responsáveis pela localização do navio no espaço, bem como pelo sucesso da viagem náutica, não residiriam em indivíduos, mas “[...] nas interações complexas dentro de um ambiente que inclui atores humanos e não humanos" (Hayles, 1999, p. 288).

As consequências do pensamento de Hutchins são essenciais para a tese da hipercognição. Como aponta Hayles (1999, p. 289), os seres humanos se engajariam diariamente em sistemas cuja capacidade cognitiva total excederia em muito o conhecimento de um indivíduo isolado. Exemplos poderiam ser encontrados em sistemas de ignição de carros eletrônicos, microondas computadorizados que auto ajustam os níveis de potência e relógios que se comunicam por ondas de rádio, corrigindo automaticamente o horário e, mais recentemente, como se sustenta, nas tecnologias NBIC. Para Hayles (1999, p. 289), a primazia do sistema cognitivo sociocultural proposto por Hutchins mostraria que "humanos modernos são capazes de maior sofisticação cognitiva que homens da caverna não porque são mais espertos [...] mas porque construíram ambientes mais espertos nos quais trabalhar" (Hayles, 1999, p. 289).

1980, Randall Beer publicou a obra Intelligence as Adaptative Behavior, com a sugestão de que a inteligência, ao invés de ser vista como a inclinação única dos seres humanos para possuir habilidades linguísticas e raciocínio lógico, deveria ser tomada como "[...] a capacidade mais universal dos animais de lidar continuamente com o mundo complexo, dinâmico e imprevisível em que vivem” (Beer, 1989, p. xvi). Logo, o ambiente passaria a ter um papel fundamental, pois, segundo Beer (1989, p. 12), à luz do conceito de comportamento adaptativo (adaptative behavior), o que de fato permitiria que os seres humanos tivessem funções cognitivas ampliadas em relação aos demais seres vivos seria a capacidade de se adaptar, momento a momento, às contingências que decorrem da interação com o ambiente externo. $\mathrm{O}$ desenvolvimento de agentes artificiais inteligentes dependeria, portanto, da compreensão dessa capacidade adaptativa. Em 1995, David Kirsh propôs, no artigo "The intelligent use of space", que o ambiente poderia ser utilizado para simplificar as tarefas cognitivas dos seres humanos. "[...] Quando usamos bem o espaço, muitas vezes podemos reduzir o tempo e as demandas de memória de nossas tarefas a níveis viáveis" (Kirsch, 1995, p. 32), o que, por sua vez, aumentaria a confiabilidade da execução e a quantidade de tarefas que poderiam ser feitas de uma única vez. 
A partir desses antecedentes, Andy Clark e David Chalmers iniciam o artigo "The Extended Mind", de 1998, com a seguinte reflexão: onde a mente termina e o resto do mundo começa? A resposta estaria no externalismo ativo, em que, como já mencionado, o ambiente teria um papel dinâmico no processo de cognição. Para ilustrar esse ponto de vista, Clark e Chalmers (1998, p. 07) consideraram três casos de resolução de problemas feitos por seres humanos: a) uma pessoa estaria sentada em frente à tela de um computador, que mostraria imagens bidimensionais de vários formatos geométricos, ocasião em que seria solicitada a responder quais imagens caberiam em determinados espaços. Para cumprir essa tarefa, a pessoa deveria fazer uma rotação mental das formas geométricas de acordo com os espaços disponíveis apresentados; b) uma pessoa estaria sentada em frente à mesma tela de computador, porém, desta vez, além da rotação mental, seria possível a utilização de um botão que girasse a figura na tela; c) uma pessoa, em um futuro ciberpunk, estaria sentada em frente à tela de um computador. No entanto, tal pessoa teria um implante neural que a permitiria girar a figura tão rápido quanto o botão disponibilizado no caso anterior. Essa pessoa (com o chip instalado) deveria optar, por razões de demanda de atenção e atividade concorrente no cérebro, se iria utilizar o implante ou se faria a rotação mental da forma tradicional.

Quanto de cognição estaria presente nos três casos? Para Clark e Chalmers (1998, p. 07), todos os casos seriam similares, pois a hipótese do implante neural (c) estaria próxima da rotação mental tradicional (a) e o caso do botão (b) desempenharia o mesmo tipo de estrutura computacional do caso do implante (c), em que pese estar distribuído entre o computador e o agente (e não simplesmente internalizada no agente). Além disso, os auotres indagam: se a rotação na hipótese do implante neural (c) se apresenta como cognição, por qual motivo a utilização do botão (b) seria diferente?

Para Clark e Chalmers (1998, p. 08), o ponto principal dessa discussão não deveria se concentrar na presença de recursos computacionais externos avançados, mas, pelo contrário, no fato de que os seres humanos teriam a tendência geral de depender de apoios do ambiente. Daí a defesa de que o mundo faz parte do processo cognitivo. Logo, a proposta de mente estendida de Clark e Chalmers (1998, p. 08) advoga que o cérebro 
dos seres humanos teria evoluído de forma a confiar na presença de um ambiente externo manipulável ${ }^{7}$.

É nesse contexto de ampliação da cognição para fora da cabeça que o externalismo ativo se difere de sua contraparte passiva. Segundo Clark e Chalmers (1998, p. 08), com seus exemplos, o ser humano estaria conectado a uma entidade externa por meio de uma interação bidimensional (two-way interaction), a qual criaria um sistema acoplado capaz de originar, ao fim e ao cabo, um único sistema cognitivo. Para esses autores, todos os componentes desse sistema teriam um papel causal ativo e governariam “[...] em conjunto o comportamento da mesma maneira que a cognição geralmente faz. Se removermos o componente externo, a competência comportamental do sistema diminuirá" (Clark \& Chalmers, 1998, p. 09), como se uma parte do próprio cérebro fosse retirada. "Nossa tese é que esse tipo de processo acoplado conta igualmente bem como um processo cognitivo, esteja ou não completamente na cabeça" (Clark \& Chalmers, 1998, p. 09). Logo, diferentemente do externalismo passivo, tanto o semântico quanto o social, no externalismo ativo as características do ambiente teriam um impacto direto no organismo e no comportamento do indivíduo, pois estariam atrelados ao organismo humano de modo que as partes relevantes do mundo, na visão de Clark e Chalmers (1998, p. 09), não estariam mais apenas suspensas ao final de uma longa cadeia causal. Além disso, a defesa de uma cognição estendida não seria, para os autores, somente uma mudança terminológica, mas poderia ensejar uma diferença significativa inclusive na metodologia de investigação científica: "Métodos explicativos que antes poderiam ter

\footnotetext{
${ }^{7}$ Um exemplo disso, segundo Clark e Chalmers (1998, p. 08) já teria sido identificado no trabalho de David Kirsh e Paul Maglio, de 1994, relativo ao jogo Tetris. No Tetris, relembrando, os usuários precisam mudar a forma geométrica e a direção de peças que caem constantemente, encaixando-as nos espaços formados na base da estrutura. $\mathrm{O}$ estudo citado demonstrou que a rotação mental das peças demorava em torno de 1000 milissegundos, mas que o tempo caia para 100 milissegundos quando o mesmo processo era feito através do botão de rotação física disponível para o jogador: “[...] a rotação física é usada não apenas para posicionar um formato pronto para caber em uma abertura, mas geralmente para ajudar a determinar se o formato e a abertura são compatíveis" (Clark \& Chalmers, 1998, p. 08). Para Clark e Chalmers (1998, p. 08), tal exemplo representaria uma ação epistêmica, cuja característica, além de alterar o mundo, estaria em ajudar e em aumentar os processos cognitivos. A ação epistêmica, por sua vez, espalharia um crédito epistêmico, situação na qual - como colocam Clark e Chalmers (1998, p. 08) para defender a proposta de uma cognição estendida -, se uma pessoa, ao ser demandada para realizar certa tarefa, não hesitasse em reconhecer que o mundo funcionou como parte do processo cognitivo para a obtenção da resposta desejada, então aquela parte do mundo deveria ser considerada, sem sombra de dúvidas, como parte do processo cognitivo.
} 
sido considerados apropriados apenas para a análise de processos 'internos' agora estão sendo adaptados para o estudo dos aspectos externos" (Clark \& Chalmers, 1998, p. 10).

Em virtude de tais possibilidades, Clark e Chalmers (1998, p. 11) especulam que, no futuro, os seres humanos seriam capazes de conectar módulos extras ao cérebro (como, por exemplo, para aumentar a memória de curto prazo). No entanto, mesmo nesses casos, "[...] os processos envolvidos são tão cognitivos como se estivessem lá [no cérebro] o tempo todo" (Clark \& Chalmers, 1998, p. 11). Isso ocorreria pelo fato de que a seleção natural teria permitido o surgimento de um cérebro biológico que prosperou por intermédio da manipulação do meio externo, favorecendo, com isso, uma capacidade de "parasitar" o ambiente local e também uma habilidade de redução da sobrecarga de memória. A linguagem seria um modelo capaz de ilustrar tal perspectiva, demonstrando como, de fato, os processos cognitivos são estendidos no mundo (Clark \& Chalmers, 1998, p. 11). "Pense em um grupo de pessoas fazendo um brainstorming em torno de uma mesa ou em um filósofo que pensa melhor escrevendo, desenvolvendo suas ideias na medida em que elas avançam" (Clark \& Chalmers, 1998, p. 11). Na visão desses autores, pode ser que a linguagem tenha evoluído, ao menos em parte, para possibilitar que os seres humanos tivessem essas extensões de recursos em sistemas ativamente acoplados como, por exemplo, no contexto cognição-ambiente: "palavras e símbolos externos são, portanto, fundamentais entre os vórtices cognitivos que ajudam a constituir o pensamento humano" (Clark \& Chalmers, 1998, p. 12).

Há questões complementares no artigo "The Extended Mind", de Clark e Chalmers, que vão além do processo cognitivo, como a relação da mente com o ambiente: “[...] argumentaremos que as crenças podem ser constituídas parcialmente por características do ambiente, quando essas características desempenham o tipo certo de papel na condução de processos cognitivos" (Clark \& Chalmers, 1998, p. 12, grifos do original). Como o propósito deste trabalho é sustentar a tese da hipercognição, é suficiente apresentar a cognição estendida como pressuposto para o aumento da cognição dos seres humanos.

Para fins filosóficos, seria possível traçar um paralelo entre a mente estendida e a hipercognição, até porque ambas se refeririam a casos de influência ativa do meio externo na cognição, estando a hipercognição, nesse contexto, fundamentada na hipótese de que os artefatos cognitivos da Convergência Tecnológica representariam uma ação 
epistêmica (ao permitir um aumento do processo cognitivo do indivíduo) e gerariam um crédito epistêmico (ao demonstrar que as tecnologias NBIC seriam parte indissociável de tal processo cognitivo). A principal diferença entre os modelos é que, na hipercognição, o sistema cognitivo único (formado pela interação entre o indivíduo e o meio) seria capaz de gerar informação nova, não disponível isoladamente nem para o agente nem para o artefato. Com isso, seria possível sustentar que a hipercognição, ainda que atuando individualmente, produziria um aumento real da capacidade cognitiva dos seres humanos como um todo.

Dentre todos os detratores do externalismo ativo e da mente estendida, a crítica mais contundente foi elaborada por Fred Adams e Ken Aizawa (2001), no artigo intitulado "The bounds of cognition", cujo objetivo era clarificar o que se entenderia por processos cognitivos. Para esses autores (2001, p. 43), ainda que a cognição transcraniana fosse uma possibilidade lógica e nomológica, não haveria razões suficientes para aceitála. "Para nós [...] o crânio não constitui um limite teórico significativo. Mais especificamente, isso significa que estar dentro do crânio não pode ser a marca do cognitivo" (Adams \& Aizawa, 2001, p. 46). Nesse contexto, os autores (Adams \& Aizawa, 2001, p. 47) asseveraram que todos os processos cognitivos encontrados no mundo real aconteceriam nos limites do cérebro e que seriam remotas as chances de que ferramentas utilizadas pelos seres humanos pudessem ter as mesmas propriedades cognitivas do cérebro biológico.

Discorrendo acerca do experimento mental que iniciava o "The Extended Mind", em que uma pessoa precisava fazer a rotação de imagens geométricas, sendo possível girá-las mentalmente (caso a); girá-las através de um botão físico (caso b) ou girá-las por intermédio de um implante neural (caso c), Adams e Aizawa (2001, p. 54) diferentemente de Clark e Chalmers, para quem os três casos seriam similares argumentaram que tais casos não poderiam ser considerados idênticos em termos cognitivos. Isso porque, de acordo com Adams e Aizawa (2001, p. 54), no caso a o indivíduo usaria representações mentais dos blocos no processo de rotação das peças. Contudo, no caso b, os blocos não seriam representações, mas sim os blocos em si mesmos. Ademais, segundo Adams e Aizawa (2001, p. 54), ao apertar o botão físico no caso b, o agente alteraria o circuito elétrico cerebral, fazendo com que os elétrons fossem disparados de maneira diferente em relação ao caso a, o que, por sua vez, alteraria a 
dinâmica do processo cognitivo. "Esse tipo de processo causal certamente não é o mesmo que qualquer processo cognitivo, ou qualquer fragmento de um processo causal, no cérebro" (Adams \& Aizawa, 2001, p. 54).

Logo, os autores sustentaram que, no caso $b$, existiria atividade muscular (pressionar o botão) associada à cognição, o que levaria à utilização de mecanismos de decisão cognitiva distintos por parte do indivíduo, uma vez que "[...] devem existir mecanismos de atenção para colocar em ação os mecanismos de memória e devem existir mecanismos de memória que armazenem para o agente as informações sobre a existência do botão e seu uso" (Adams \& Aizawa, 2001, p. 55). Essa conclusão originou o seguinte questionamento retórico: "É demais dizer que a ciência da psicologia cognitiva como a conhecemos deixaria de existir sem a atenção a tais diferenças na experimentação?” (Adams \& Aizawa, 2001, p. 55). Em relação ao caso c, que se passaria em um futuro ciberpunk, os autores (Adams \& Aizawa, 2001, p. 55) afirmaram que se trataria apenas de uma confusão acerca das distinções entre os casos a e b: eis que Clark e Chalmers poderiam ter alinhado o caso c com o caso a, ou o caso c com o caso b, mas jamais o caso c com os casos a e b concomitantemente ${ }^{8}$.

Para Adams e Aizawa (2001, p. 60), a cognição transcraniana seria uma possibilidade em aberto, mas não da maneira como aduzida pelos seus defensores, tampouco existente em hipóteses de uma pessoa usando um martelo, escrevendo em um computador ou se conectando à Internet. “[...] embora seja possível construir uma máquina de Turing universal com latas de cerveja e pombos ou com a população da China, isso provavelmente nunca foi feito e nunca será" (Adams \& Aizawa, 2001, p. 60). A razão para tanto estaria no fato de que, ao contrário dos processos intracranianos, a cognição transcraniana não seria capaz de originar regularidades científicas (Adams \& Aizawa, 2001). "Não há leis abrangendo humanos e o seu uso de ferramentas acima das leis da cognição humana intracraniana e as leis das ferramentas físicas" (Adams \& Aizawa, p. 61). Como forma de demonstrar essa perspectiva, Adams e Aizawa (2001, p. 61) argumentaram que bastaria se pensar, de um lado, na miríade de possibilidades advindas da memória humana, as quais estariam sujeitas a regularidades (semelhantes a leis), além de serem sensíveis às tarefas (memórias para imagens, rostos, cheiros e assim

\footnotetext{
${ }^{8}$ Como fica explícito no artigo, Adams e Aizawa (2001) deixam ao leitor a tarefa de continuar a desenvolver as diferenças entre os casos c e os casos a e b.
} 
por diante) e, de outro lado, na gama de ferramentas que os seres humanos utilizaram como auxílios mnemônicos, os quais incluiriam, em rol exemplificativo, agendas, catálogos, álbuns de fotos, mapas, computadores e listas de “coisas a fazer”. “[...] Quais são as chances de haver regularidades interessantes que abranjam os seres humanos interagindo com todos esses tipos de ferramentas? Praticamente zero, nós especulamos" (Adams \& Aizawa, 2001, p. 61). Para esses autores (Adams \& Aizawa, 2001, p. 62), mesmo que a marca do cognitivo não fosse um processo intracraniano, pois que a cognição poderia estar apenas acidentalmente - e não necessariamente - dentro do crânio, haveria pouca esperança de se encontrar uma ciência de processos transcranianos. "O único tipo de nova ciência na área será uma ciência de processos que ocorrem por via intracraniana" (Adams \& Aizawa, 2001, p. 62).

Em complemento à análise sobre a marca da cognição, que, como visto, com pouca probabilidade seria um evento transcraniano, Adams e Aizawa (2001, p. 56) defenderam que a proposta de Clark e Chalmers possuiria também uma falácia relativa ao argumento do acoplamento ${ }^{9}$ (coupling argument). Tal argumento estaria presente no "The Extended Mind", quando Clark e Chalmers se referiram ao fato de que um ser humano poderia interagir bidimensionalmente com um artefato externo e, a partir disso, criar um único sistema cognitivo de modo que o processo de cognição ocorreria mesmo quando não completamente dentro da cabeça. Para Adams e Aizawa (2001, p. 56), todavia, o mero acoplamento de algum processo com o ambiente não deveria levar à conclusão de que esse processo pudesse se estender em relação ao ambiente mais amplo. Neste contexto, de acordo com Adams e Aizawa (2001, p. 56), uma analogia poderia ser feita com o rim e a sua responsabilidade por fazer a filtragem das impurezas do sangue. Enquanto o rim seria influenciado pelo bombeamento de sangue feito pelo coração e pelo tamanho dos vasos sanguíneos no sistema circulatório, os quais interagiriam diretamente com o rim, nada poderia ser dito acerca de uma suposta filtragem das impurezas fora do rim. "Portanto, um processo $P$ pode interagir ativamente com seu ambiente, mas isso não significa que P se estenda ao seu ambiente" (Adams \& Aizawa, 2001, p. 56). Ademais, Adams e Aizawa (2009) asseveraram que a falácia do acoplamento seria o equívoco mais comum entre os defensores da mente estendida, acrescentando que se neurônios que

\footnotetext{
${ }^{9}$ Essa visão também foi defendida por Adams e Aizawa (2010), no artigo "Defending the bounds of cognition", e por Robert Rupert (2004), no artigo "Challenges to the Hypothesis of Extended Cognition".
} 
levassem a uma junção neuromuscular fossem acoplados com os músculos que eles inervam, não se seguiria daí que os neurônios fossem parte do corpo muscular, ou, no mesmo sentido, que se a liberação de neurotransmissores na junção neuromuscular fosse acoplada ao processo de contração muscular seria incorreto dizer que a liberação corresponderia a um segmento da contração muscular. Para esses autores (Adams \& Aizawa, 2009), não bastaria afirmar que um processo cognitivo ocorreria quando fosse acoplado com um agente cognitivo, pois isso somente retornaria ao questionamento sobre o que, de fato, seria a "marca do cognitivo". Fazendo justiça a Clark e Chalmers, porém, Adams e Aizawa (2009) ressaltaram que uma das maiores deficiências das teorias cognitivas contemporâneas estaria justamente em pacificar um modelo sobre a cognição. Mesmo assim, como ficou claro nas propostas de Adams e Aizawa (2001, p. 63-4), ainda que não houvesse consenso sobre tal marca, “[...] podemos ver o suficiente dessa marca para identificar que os processos cognitivos são provavelmente processos ligados às fronteiras do cérebro" (Adams \& Aizawa, 2001, p. 64), finalizando que os tipos de processos que ocorrem dentro do cérebro possuiriam certas regularidades que não seriam compartilhadas com os sistemas acoplados (como cérebro e ferramentas, por exemplo).

Em relação ao problema apresentado por Adams e Aizawa (2001, p. 61) relativamente à impossibilidade de a cognição transcraniana originar regularidades científicas, o que acarretaria, em primeiro lugar, não ser viável uma ciência da mente estendida e, em segundo lugar, a necessidade de se contentar com uma teoria das propriedades mentais internas separada de todo o restante -, os contra-argumentos de Clark (2010, p. 50) demonstraram que não seria sensato julgar, de maneira precoce, a impossibilidade absoluta de se virem a descobrir regularidades científicas em qualquer domínio. De acordo com o autor (Clark, 2010, p. 50), bastaria se recordar do sucesso recente da teoria da complexidade e na descoberta de alguns princípios unificadores aplicáveis a diferentes escalas. "Parece que agora existem leis de energia que explicam [...] sistemas que variam da distribuição de tamanho das cidades às frequências de ocorrência de palavras e à frequência de avalanches em montes de areia" (Clark, 2010, p. 50). Além disso, embora existissem diferenças físicas básicas entre os processos de escrita e leitura a partir do computador de Otto e a partir de sua memória biológica, poderia haver, em algum nível, um grau de descrição desses sistemas que integrassem os processos em um único conjunto (Clark, 2001). Assim, para Clark (2010, p. 50), as 
objeções de Adams e Aizawa seriam semelhantes à alegação de um oponente dos modelos simbólicos de processamento mental de que em decorrência das profundas diferenças físicas entre cérebros e computadores de von Neumann não seria possível existir uma ciência que viesse a tratar tais processos de uma maneira unificada. Ou, ainda, como se fosse possível "[...] concluir que pelo fato de que a química e a geologia empregarem técnicas e vocabulários distintos que o crescente estudo da geoquímica está condenado desde o início" (Clark, 2010, p. 50). Com efeito, seria parte do trabalho de uma ciência especial estabelecer o quadro pelo qual diferentes fenômenos pudessem ser entendidos à luz de uma única explicação, acrescentando que seria inexigível que todos os elementos se comportassem de acordo com as mesmas leis, até porque poderiam existir muitas subregularidades, dos mais variados tipos (Clark, 2010). À guisa de conclusão, Clark (2010, p. 51) vaticinou, em postulado que também se aplica à hipercognição, que o estudo da mente precisaria "[...] abraçar uma variedade de paradigmas explicativos diferentes, cujo ponto de convergência reside na produção de comportamento inteligente" (Clark, 2010, p. 51).

Em relação à marca do cognitivo, que Adams e Aizawa (2001, p. 62) defenderam ser provavelmente um evento intracraniano, Rowlands (2009, p. 13) relembrou que em nenhum momento a hipótese da mente estendida abarcaria a ideia de que os processos cognitivos ocorreriam apenas externamente, pois, em todos os casos, ou (a) tais processos seriam internos ou (b) seriam acoplados em operações que contemplassem ambos os aspectos internos e externos: "processos cognitivos sempre contém um elemento interno não eliminável” (Rowlands, 2009, p. 13). Segundo Rowlands (2009, p. 14), a concepção tradicional acerca da cognição demonstraria que os processos cognitivos seriam pensados espacialmente dentro dos limites de um sujeito cognitivo, o que, em um primeiro momento, poderia constituir uma vantagem do internalismo, posto que aplicável ao caso a seguinte máxima: "Um processo cognitivo $\mathrm{P}$ pertence ao sujeito $\mathrm{S}$ se e somente se $\mathrm{P}$ ocorrer dentro de S" (Rowlands, 2009, p. 14).

Entretanto, como argumentou Rowlands (2009, p. 10), compreender o sentido em que os processos de cognição teriam um "dono" seria uma das tarefas mais difíceis na análise da marca do cognitivo ${ }^{10}$. Como afirmou Rowlands $(2009$, p. 10), posição que

\footnotetext{
${ }^{10}$ Para ilustrar tal dificuldade, Rowlands (2009, p. 16) se valeu de uma comparação encontrada em um processo biológico não cognitivo, a digestão, em que seria simples para uma pessoa perceber que a digestão
} 
é endossada neste trabalho, se a marca do cognitivo ainda seria um desafio para a mente estendida, o mesmo poderia ser dito para o internalismo, pois um problema para ambos não deveria ser um problema específico de apenas um.

Sobre a falácia do acoplamento, em que Adams e Aizawa (2001, p. 56) defenderam que artefatos externos (como canetas e lápis) não poderiam ser parte da cognição, posto que as únicas entidades intrinsicamente cognitivas seriam os cérebros, é importante recordar que a seleção natural já teria dotado certos organismos com habilidades de incorporar o mundo externo ao seu modo de vida e à sua cognição. Em 1982, Richard Dawkins (2008, p. 4) escreveu a obra intitulada The Extended Phenotype: the long reach of the gene, cujo objetivo era defender um ponto de vista chamado de "fenótipo estendido", na acepção de que em muitos seres vivos, de insetos a mamíferos, os genes contribuíram para a utilização de ferramentas artificiais em prol da sobrevivência do indivíduo e da perpetuação de seu material genético. $\mathrm{O}$ exemplo clássico seria a represa construída por castores, que se aproveitariam de galhos, troncos, lamas e pedras para criarem um lago artificial dentro de um rio e onde edificariam sua morada, utilizada para o acasalamento e para o cuidado com a prole ${ }^{11}$. Seja como for, retomando o núcleo

estaria ocorrendo em seu corpo e não dentro do corpo de outro indivíduo qualquer. Todavia, para Rowlands (2009, p. 16), essa clarividência seria falha, uma vez que poderiam ser imaginados casos em que a digestão acontecesse externamente, sobretudo nas hipóteses de ausência de produção de certas enzimas no trato digestivo. "A solução, drástica e implausível, mas ainda assim uma solução, é redirecionar o trato para um dispositivo externo onde as enzimas relevantes são adicionadas, antes de direcionar o trato de volta ao corpo" (Rowlands, 2009, p. 16), cenário no qual, portanto, a digestão de uma pessoa necessitaria de ajuda externa, ainda que a digestão, por si só, não deixasse de ser dessa pessoa. O que Rowlands (2009, p. 16) pretendeu mostrar com esse exemplo era que, subjacente à digestão, o que definiria um processo digestivo seria a realização da função digestora adequadamente, sendo irrelevante o fato de tal processo ser ajudado por um dispositivo externo, contanto que a digestão, ao fim e ao cabo, acontecesse, pois a conexão entre propriedade e a localização do processo digestivo seria apenas contingente. "[...] mais uma vez, o que sustenta essa intuição é a ideia de que um processo digestivo é meu, é a função adequada da digestão sendo cumprida em relação a mim: é a minha comida que está sendo decomposta" (Rowlands, 2009, p. 16). Para ele (2009, p. 16), o modelo da digestão poderia ser importado para a cognição para demonstrar que ser dono ou titular de um processo cognitivo não implicaria a impossibilidade da ajuda de elementos externos - o que se aproxima sobremaneira da tese da hipercognição -, além de que, na suposição de que um indivíduo utilizasse informações e recursos do ambiente (o que é pressuposto na hipercognição), essa manipulação, transformação e exploração de estruturas externas também deveria ser explicada de uma maneira irrefutável pelo internalismo.

${ }^{11}$ Outros exemplos são trazidos por Kevin Kelly (2011, p. 27): “[...] Os chimpanzés criavam (e, é claro, ainda criam) ferramentas de caça, usando gravetos para extrair cupins da terra e pedras para quebrar nozes. Os próprios cupins constroem vastas torres de lama que transformam em seus lares. As formigas têm rebanhos de afídeos e cultivam fungos em jardins. Os pássaros produzem tecidos complexos e cheios de folhas e pedaços e madeira para construírem seus ninhos. E alguns polvos procuram conchas para carregarem como lares portáteis. A estratégia de alterar o ambiente para usá-lo como se fosse parte do próprio corpo é um truque de pelo menos meio bilhão de anos". 
da discussão, Richard Menary (2006, p. 332) asseverou que as críticas internalistas ficaram restritas apenas aos processos e veículos externos. E isso por conta de uma compreensão equivocada do princípio da paridade, cuja versão simplificada poderia ser enunciada da seguinte maneira: se os processos externos fossem localizados no crânio, eles seriam chamados de cognitivos. Logo, ainda que não estejam dentro da cabeça, mesmo assim eles devem ser chamados de cognitivos. De acordo com Menary (2006, p. 333), os internalistas entenderam que os veículos externos seriam cognitivos conquanto casualmente acoplados aos indivíduos, o que seria um erro, pois o ponto a ser destacado seria a integração dinâmica entre tais processos (internos e externos) para a realização de uma tarefa. "O objetivo não é mostrar que os artefatos passam a fazer parte da cognição apenas porque são casualmente acoplados a um agente cognitivo pré-existente, mas explicar por que X e Y são tão coordenados que, juntos, funcionam como Z” (Menary, 2006, p. 334). Segundo esse autor (2006, p. 334), ainda que, evidentemente, os papéis dos veículos internos e externos no desempenho de uma atividade sejam diferentes, não se poderia deixar de lado a complementaridade entre eles.

Sustenta-se, a partir do pensamento de Menary (2006, p. 334), que seria a coordenação (ou acoplamento recíproco) entre processos externos e internos que advogaria em favor da hipótese da mente estendida, até porque “[...] pode haver casos equivalentes em que a coordenação dos processos é exclusivamente interna e ainda leva aos mesmos resultados" (Menary, 2006, p. 334). Com efeito, como apontaram Chemero e Silberstein (2008, p. 129), não haveria razões a priori pelas quais os fenômenos tivessem explicações internalistas integrais. Alguns dependeriam de testemunhos do corpo, enquanto outros demandariam clarificações somente possíveis com a integração dos sistemas cérebro-corpo-ambiente. Como defendido, é nesta última categoria que se encontra a hipercognição. As críticas e às ideias de Clark e Chalmers, como anunciado, tiveram por objetivo refinar os argumentos que serão transpostos para a hipercognição.

Considera-se, em que pesem as opiniões em contrário, que não há motivos filosóficos para se abandonarem as premissas de que a cognição (e a mente) poderia ser ampliada para além dos limites do cérebro. A última análise será em uma verticalização da mente estendida. Com Clark e por Clark, na obra Natural-born cyborgs: Minds, technologies, and the future of human intelligence, de 2003, os seres humanos já poderiam ser considerados ciborgues, não no sentido de fusão da carne com máquinas, 
mas na acepção de que haveria um sistema de pensamento e raciocínio em que as mentes e os selves estariam espalhados por todo o cérebro biológico e também por circuitos não biológicos. "Com relação aos seres humanos, eu quero te convencer, eles são ciborgues natos" (Clark, 2003, p. 3). A razão pela qual se ratifica o pensamento de Clark é a possibilidade de explicação, ou ponderação, da forma como a cognição se operaria na mente do Homo sapiens de maneira biológica (mesmo que não se utilize um discurso biologicista). Logo, da mente estendida se chegaria à mente híbrida, fechando-se, com isso, o primeiro referencial teórico em torno da hipercognição.

Para Clark (2003, p. 4), o processo de transformação dos seres humanos em ciborgues poderia ser comprovado através de alguns "traços fósseis cognitivos", em que se destacaria, inicialmente, o uso da língua e da contagem, que teriam evoluído para a escrita e os numerais, passando, na sequência, para as primeiras formas de registro impresso e, mais recentemente, para as codificações digitais que trariam texto, som e imagem em um formato amplamente uniforme e transmissível, aperfeiçoando-se, nos dias atuais, com os computadores, softwares e aplicativos de uso pessoal e profissional, de tal forma que, como aponta Clark (2003, p. 4), a mente dos seres humanos estaria cada vez menos dentro da cabeça. Em virtude disso, a mente passaria a depender da fusão com elementos como a caneta, o papel e os aparelhos eletrônicos. Aliás, para Clark (2003, p. 6-7), os homens teriam sido projetados pela natureza com uma profunda plasticidade neural, cuja principal característica seria fornecer a habilidade para fusões e expansões da mente.

Segundo Clark (2003, p. 10), essa inclinação nata dos seres humanos para extensões a partir do uso de ferramentas provocaria uma autotransformação profunda que explicaria a razão pela qual os homens seriam tão diferentes das demais espécies, já que, do ponto de vista biológico, não haveria uma disparidade genética muito grande. Neste cenário, a essência do ser humano, na visão de Clark (2003, p. 10), decorreria da capacidade do Homo sapiens de reestruturar e reconstruir o seu próprio circuito mental, sendo que este, por sua vez, resultaria de uma teia cada vez mais poderosa trespassada pela cultura, pela educação, pela tecnologia e pelos artefatos, aos quais se inclui, no bojo deste trabalho, as tecnologias NBIC da Convergência Tecnológica. A rigor, uma das apostas de Clark (2003, p. 22) seria a de que tão logo as interfaces bioeletrônicas cresçam em complexidade e consigam penetrar mais profundamente no cérebro, distanciando-se 
da pele e dos ossos, os seres humanos se tornarão menos resistentes à ideia de que já são genuínos ciborgues tecnológicos.

Em outra perspectiva, Clark (2003, p. 24) opina que as mais potentes tecnologias do futuro próximo serão aquelas que oferecerão uma integração e transformação do usuário com as máquinas sem a necessidade de implantes ou cirurgias, gerando-se, como se sustenta aqui, a hipercognição. A típica tecnologia ciborgue exemplar atual é o celular (Clark, 2003, p. 27), uma vez que representaria um ponto de transição crucial entre as tecnologias da primeira (canetas, papéis, diagramas) e da segunda onda (uniões biotecnológicas mais dinâmicas, personalizadas e online) dos ciborgues natos. Como aponta o autor (2003, p. 28), em muitos lugares do mundo o celular já estaria incorporado à rotina diária de milhões de indivíduos, que se sentiriam perdidos e desorientados em caso de perda do aparelho ${ }^{12}$. Clark (2003, p. 28) reforça que os celulares seriam tecnologias ciborgues por forçarem uma fusão do homem com a máquina sem a necessidade de incisões ou implantes cirúrgicos, na extensão de que tais tecnologias, mesmo que não penetrantes, teriam poder suficiente para transformar a vida, os projetos e o próprio senso de capacidade dos seres humanos.

Ademais, segundo Clark (2003, p. 67), o oportunismo neural facilitaria o desenvolvimento de outra estratégia eficaz de resolução dos problemas, consistente na preferência do cérebro humano por uma meta conhecimento ao invés de um conhecimento específico. "Meta conhecimento é conhecimento sobre como adquirir e explorar informação, em vez de conhecimento específico sobre o mundo. Não se trata de saber muito, mas sim de saber como descobrir" (Clark, 2003, p. 67). Desse modo, o autor (2003, p. 69) argumenta que, em se tratando de informação, tanto faz se ela está armazenada dentro do organismo biológico ou no mundo externo, pois o que importa seria a capacidade de recuperação e uso imediato de tal informação assim que requerida. E, nesse ponto, os cérebros plásticos e as mentes híbridas dos ciborgues natos seriam verdadeiros prodígios, já que, como aponta os cérebros dos seres humanos não se configurariam como meros receptores passivos de informação, tais como os rádios e a televisão, que simplesmente converteriam os sinais em algum tipo de aparato visual ou

\footnotetext{
${ }^{12}$ Ressalta-se que Clark mencionou o exemplo do aparelho celular há quase duas décadas. Atualmente seu exemplo é mais amplamente ilustrativo.
} 
auditivo; pelo contrário, os cérebros humanos seriam plásticos o suficiente para aprender diversas novas formas de ações em potencial (Clark, 2003, p. 95).

Logo, de acordo com Clark (2003, p. 137), os elementos não biológicos teriam o atributo de fornecer ainda mais capacidades de atuação e de contribuir com formas adicionais do senso existencial dos homens, sobretudo nas questões sobre o que, como e quando algo poderia ser feito, que decisões tomar e que escolhas realizar. "Nós somos 'soft-selves', continuamente abertos à mudança e inclinados a vazar pelos confins da pele e do crânio, anexando mais e mais elementos não biológicos como aspectos da maquinaria da própria mente" (Clark, 2003, p. 137). É por essa razão que Clark (2003, p. 142) rejeita um viés pós-humanista, em especial na perspectiva de uma transformação ontológica do ser humano a partir da fusão com as máquinas, afirmando que os homens já seriam, por natureza, peritos na tarefa de incorporar material não biológico em suas rotinas físicas e cognitivas. Assim, no entendimento de Clark (2003, p. 174), a simbiose entre homens e máquinas seria algo que decorreria naturalmente, sobretudo na acepção de que os processos cognitivos, que eventualmente marcariam a natureza humana, seriam dependentes de ajudas externas.

Não bastasse, há ressalvas de Clark (2003, p. 141) à proposta - encampada, principalmente, pela psicologia evolutiva - de que o cérebro humano consistiria em um conjunto de mecanismos psicológicos envolvidos e que foram projetados pela seleção natural para resolverem os problemas enfrentados pelos ancestrais humanos nas savanas da África durante a história evolutiva da espécie. Para esse autor (Clark, 2003, p. 141), tal visão criaria um viés determinista e delimitador do potencial da mente moderna, esquecendo-se, nessa análise, que os cérebros humanos também teriam sido projetados pela natureza para serem profundamente abertos a reconfigurações, em especial aquelas decorrentes do contato com a tecnologia. "O cérebro humano é o maior camaleão mental da natureza. Pulsado e instruído por plasticidade nata, ele está pronto para profundas fusões com a rede circundante de símbolos, cultura e tecnologia" (Clark, 2003, p. 197). Portanto, o caminho em direção a uma intensa fusão biotecnológica seria a expressão direta da característica mais acentuada da espécie Homo sapiens, segundo Clark (2003, p. 194), uma vez que os homens seriam seres híbridos marcados pela união de uma natureza biológica com uma rede linguística, cultural e tecnológica multifacetada. Neste sentido, o autor (Clark, 2003, p. 198) indica que as fronteiras mais significativas do século 
XXI não serão aquelas do espaço, mas sim aquelas existentes na mente, porquanto as tecnologias mais importantes possibilitarão que o pensamento humano vá até onde nenhum pensamento animal tenha ido antes. "São nossas mentes metamorfas, não nossos corpos espacialmente itinerantes, que irão expressar mais completamente nossa profunda natureza ciborgue" (Clark, 2003, p. 198).

Por fim, para Clark (2003, p. 198), não haveria o que se temer com relação aos ciborgues ou ao pós-humanismo, pois se a natureza básica dos homens seria a de permitir anexação, exploração e incorporação de ferramentas não biológicas para dentro da mente, então a questão não estaria tanto no fato de os seres humanos deverem ou não optar por tais fusões, mas, em sentido contrário, corresponderia às discussões sobre as formas em que essas uniões ciborguianas biotecnológicas poderiam ser esculpidas e afeiçoadas para oferecer o caminho do futuro para o Homo sapiens. Aí está, com essa ideia de mente híbrida, a via sedimentada para a hipercognição. Do externalismo passivo, com a proposta de que os significados não estão na cabeça, ao anti-individualismo; do externalismo ativo, com o sistema cognitivo sociocultural à mente estendida, a hipercognição representaria uma das formas pelas quais o trans e pós-humanismo poderiam ser discutidos, demonstrando-se, ao menos na seara cognitiva, que a mente híbrida geradora de hipercognição não significaria a obsolescência do ser humano, mas apenas o estágio mais recente da interação do homem com a tecnologia.

A partir da Convergência Tecnológica, sustenta-se que as tecnologias NBIC, a despeito de terem surgido de maneira independente no campo das ciências aplicadas, são os artefatos cognitivos por excelência da hipercognição, uma vez que a mente híbrida dos seres humanos se apropriaria das ferramentas de tal ambiente sociocultural e porque, como argumentado no âmbito do externalismo ativo, a cognição não estaria apenas dentro da cabeça. Por outro lado, entende-se que dentro de NBIC o maior potencial cognitivo seria encontrado na inteligência artificial.

A hipercognição não é um resultado de melhoramento como defendido pelo transumanismo, que entende que a natureza humana precisa ser alterada para corrigir falhas ou insuficiências naturais. Pelo fato de os humanos serem naturalmente ciborgues e que realizam, portanto, interações com artefatos para produzir resultados cognitivos, a natureza humana não é ontologicamente alterada para alcançar a hipercognição. A ontologia humana, de acordo com a perspectiva do externalismo ativo, já pressupõe uma 
contínua alteração com o aprimoramento natural da sua cognição mediante interação com o meio externo, criando artefatos interativos que ampliam ainda mais sua capacidade cognitiva.

Com a nova realidade de interação com artefatos interativos sofisticados da Convergência Tecnológica NBIC, a hipercognição é uma consequência natural da ontologia humana ciborgue. Não se desconsidera, aqui, que resultados transumanistas não sejam buscados pelos humanos contemporâneos, mas o que se conclui é que a hipercognição não afeta a ontologia humana, uma vez que é resultado da sua capacidade cognitiva interativa da natureza humana ciborgue.

\section{Referências}

Adams, F. \& Aizawa, K. Defending the bounds of cognition. In: Menary, R. (Org.). The Extended Mind. Cambridge: The MIT Press, 2010.

Adams, F. \& Aizawa, K. The bounds of cognition. Philosophical Psychology, 2001, 14(1), p. 43-64. Disponível em: https://doi.org/10.1080/09515080120033571. Acessado em: 8 de janeiro de 2020 .

Beer, R. Intelligence as adaptative behavior: an experiment in computational neuroethology. San Diego: Academic Press Inc., 1989.

Bostrom, N. \& Sandberg, A. The Wisdom of Nature: An Evolutionary Heuristic for Human Enhancement. In: Savulescu, J. \& Bostrom, N. (Org.). Human enhancement. Oxford: Oxford University Press, 2010.

Burge, T. Individualism and Psychology. The Philosophical Review, 1986, 95, p. 3-45. Disponível em: https://www.jstor.org/stable/2185131?seq=1. Acessado em: 30 de dezembro de 2019.

Burge, T. Individualism and the Mental. Midwest Studies In Philosophy, 1979, p. 73121. Disponível em: https://onlinelibrary.wiley.com/doi/10.1111/j.14754975.1979.tb00374.x. Acessado em: 29 de dezembro de 2019.

Carter, A.J.; Kallestrup, J.; Orestis, S.; Pritchard, D. Varieties of Externalism. Philosophical Issues, 2014, 24, p. 63-109. Disponível em: https://onlinelibrary.wiley.com/doi/abs/10.1111/phis.12026. Acessado em: 6 de janeiro de 2020.

Chemero, A. \& Silberstein, M. Defending Extended Cognition. Proceedings of the Annual Meeting of the Cognitive Science Society, p. 129-134, 2008. Disponível em: https://escholarship.org/uc/item/2nm1b0b4. Acessado em: 14 de janeiro de 2020. 
Clark, A. Memento's Revenge: The Extended Mind, Extended. In: Menary, R. (Org.). The Extended Mind. Cambridge: The MIT Press, 2010.

Clark, A. Natural-born cyborgs: Minds, technologies, and the future of human intelligence. New York: Oxford University Press, 2003.

Clark, A. Re-inventing ourselves: The plasticity of embodiment, sensing, and mind. In: More, M. \& Vita-More, N. (Org.). The Transumanist Reader. West Sussex: John Wiley and Sons, 2013.

Clark, A. Supersizing the mind: embodiment, action, and cognitive extension. New York: Oxford University Press, 2011.

Clark, A. \& Chalmers, D. The Extended Mind. Analysis, 1998, p. 7-19.

Dawkins, R. The Extended Phenotype: The Long Reach of the Gene. Oxford: Oxford University Press, 2008.

Floyd, J. Putnam's “The Meaning of Meaning": Externalism in Historical Context. In: Ben-Menachen, Y. Contemporary Philosophy in Focus: Hilary Putnam. New York: Cambridge University Press, 2005.

Hayles, N.K. How we became posthuman: virtual bodies in cybernetics, literature, and informatics. Chicago: University of Chicago Press, 1999.

Hutchins, E. Cognition in the wild. Cambridge: MIT Press, 1995.

Kelly, K. Para onde nos leva a tecnologia. Tradução Francisco Araújo da Costa. Porto Alegre: Bookman, 2012.

Kirsh, D. The Intelligent Use of Space. Artificial Intelligence, 1995, p. 31-68. Disponível em: https://www.sciencedirect.com/science/article/pii/000437029400017U. Acessado em: 7 de janeiro de 2020.

Kurzweil, R. The singularity is near: when humans transcend biology. New York: Penguin Books, 2005.

McClelland, J.L.; Rumelhart, D.E. \& Hinton, G.E. The appeal of parallel distributed processing. In: Rumelhart, D.E. \& McClelland, J.L. Parallel distributed processing: Explorations in the Microstructures of Cognition. v. 1. Cambridge: MIT Press, 1986.

Menary, R. Attacking the Bounds of Cognition. Philosophical Psychology, 2006, p. 329-344. Disponível em:

https://www.tandfonline.com/doi/abs/10.1080/09515080600690557. Acesso em $13 \mathrm{de}$ janeiro de 2020.

Putnam, H. Mind, Language and Reality: Philosophical Papers. v. 2. New York: Cambridge University Press, 1975. 
Putnam, H. Reason, Truth and History. New York: Cambridge University Press, 1981.

Putnam, H. Representation and Reality. Cambridge: The MIT Press, 1991.

Putnam, H. The development of externalist semantics. Theoria, 2013, 79(3), p.192-203.

Roco, M.C. \& Bainbridge, W.S. Nanotechnology, Biotechnology, Information Technology, and Cognitive Science (NBIC). In: Roco, M.C. \& Bainbridge, W.S. (Org.). Converging Technologies for Improving Human Performance: Nanotechnology, Biotechnology, Information Technology and Cognitive Science. Dordrecht, 2003.

Rowlands, M. Extended cognition and the mark of the cognitive. Philosophical Psychology, 2009, 22(1), p. 1-19. Disponível em:

doi.org/10.1080/09515080802703620. Acessado em: 11 de janeiro de 2020.

Rowlands, M. Externalism: Putting Mind and World Back Together Again. Cheshan: Acumen Publishing Limited, 2003.

Rupert, R. Challenges to the Hypothesis of Extended Cognition. Journal of Philosophy, 2004, p. 389-428. Disponível em:

https://www.researchgate.net/publication/239452961_Challenges_to_the_Hypothesis_o f_Extended_Cognition. Acessado em: 10 de janeiro de 2020 .

Santaella, L. O retorno em espiral do pós-humano. In: Aiub, M.; Gonzalez, M.E.Q. \& Broens, M.C. (Org.). Filosofia da mente, ciência cognitiva e o pós-humano: para onde vamos? São Paulo: FiloCzar, 2015.

Spohrer, J. NBICS (Nano-Bio-Info-Cogno-Socio) Convergence to Improve Human Performance: Opportunities and Challenges. In: Roco, M.C. \& Bainbridge, W.S. (Org.) Converging Technologies for Improving Human Performance: Nanotechnology, Biotechnology, Information Technology and Cognitive Science. Dordrecht, 2003.

Suchman, L.A. Plans and Situated Actions: The problem of human-machine communication. Palo Alto: Xerox, 1985.

Suchman, L.A. Human-machine reconfigurations: Plans and Situated Actions. Cambridge: Cambridge University Press, 2007. 